\author{
Sophie Nivoix \\ CEREGE - IAE de Poitiers \\ Faculté de Droit et Sciences Sociales de Poitiers \\ 93 Avenue du recteur Pineau \\ 86000 Poitiers, France \\ Tel (+33) 549454124 \\ E-mail: sophie.nivoix@univ-poitiers.fr \\ and \\ Pascal Nguyen \\ Faculty of Commerce and Economics \\ University of New South Wales \\ Sydney NSW 2052, Australia \\ Tel (+61) 293855773 \\ Fax (+61) 293856347 \\ E-mail: pascal@unsw.edu.au
}




\title{
THE EFFECT OF GROUP AFFILIATION ON THE RISK-TAKING OF JAPANESE FIRMS
}

\begin{abstract}
This paper examines the role of keiretsu (i.e. business group) affiliation on the risk taking of Japanese firms. We find that total risk, measured by firm-level stock price volatility, is not significantly affected by keiretsu membership. The reason is that affiliated firms are characterized by lower idiosyncratic risk along with higher systematic risk. However, idiosyncratic risk varies across business groups and appears to depend upon the firm's inclination toward its group. In contrast, the higher systematic risk of group affiliates is significant for each keiretsu and every degree of group inclination. Moreover, this result remains after adjusting risk for firm characteristics and industry effects. Hence, the consequence of group affiliation may more accurately be described by higher systematic risk. This result could reflect the weaker competitive position of keiretsu affiliates.
\end{abstract}

Keywords: risk taking, systematic risk, keiretsu, group affiliation, competitive advantage

JEL Classification: G30 


\section{Introduction}

Is the risk-taking behavior of Japanese firms affected by keiretsu (i.e. business group) affiliation? Industrial economists have long described Japan's business groups as institutions designed to mitigate risk. In line with this view, Nakatani (1984) indicates that the earnings volatility of keiretsu affiliates is significantly lower. Sheard (1989) explains that the high propensity to involve trading companies in a seemingly useless manner is to facilitate risk sharing between highly-specialized manufacturing firms. Suzuki and Wright (1985) demonstrate that keiretsu member firms have a much lower bankruptcy risk than do independent firms, while Hoshi et al. (1990) emphasize the benefit of group affiliation in reducing the costs of financial distress. However, group affiliation may have a darker side. In fact, Weinstein and Yafeh (1998) associate the lower performance of group affiliates to a bias towards low risk-low return projects. ${ }^{1}$

Focusing on firm-specific (idiosyncratic) risk, Hamao et al. (2003) find evidence supportive of resource sharing in good economic times and risk mitigation in bad economic times. The decomposition of risk into a systematic and firm-specific risk component seems particularly relevant to analyzing corporate risk taking. Strategic management research emphasizes the importance of firm-specific risk in view of achieving competitive advantages. Rumelt (1974) and Porter (1980) advise firms to develop strategies to create entry barriers and build up market power, by way of product differentiation and/or economies of scale, which obviously increases (firm specific) risk. By gaining market power, firms become less exposed to market wide fluctuations; hence their lower systematic risk and higher idiosyncratic risk. Adding to this view, Lubatkin and O’Neill (1987) document that related mergers that are considered to bring economies of scale and scope and increase the firm's competitive position ${ }^{2}$ are associated with a decrease in systematic risk and an increase in firm specific risk, while unrelated mergers that are considered to bring few economic benefits have the opposite effect.

\footnotetext{
${ }^{1}$ Weinstein and Yafeh (1998) show that main banks induce affiliated firms to choose their investment projects more cautiously, leading to growth rates that are no faster than those of unaffiliated firms despite better access to capital. The negative effect of close bank relationships may have been even more important in the early postwar period than later, when the monopoly of banks gradually eroded with the development of Japan's financial markets. Their results are in line with those of Houston and James (1996) who show that firms that maintain a long-term relationship with a single creditor tend to have poor growth opportunities.

${ }^{2}$ Consistent with this argument, Walker and Hsu (2007) document that related acquisitions (i.e., in which the acquirer and the target share the same 2-digit industry code) are associated with significantly positive abnormal returns for the acquirer, whereas unrelated acquisitions are associated with negative, but statistically insignificant, abnormal returns.
} 
The purpose of this paper is to compare the total, systematic and idiosyncratic risk of affiliated and unaffiliated firms. In contrast to Hamao et al. (2003), the focus is not on aggregate idiosyncratic risk and its correlation with economic growth. Our aim is to examine whether there are consistent differences in risk taking that separate group affiliates from other firms. To that end, we investigate the risk taking behavior of affiliated firms all together and each of the main business groups separately. We also examine whether risk taking is affected by the degree of group inclination (i.e., strength of business ties with other affiliated firms).

Our results indicate that total risk is similar for affiliated and unaffiliated firms. Using a matched portfolio approach, Beason (1998) finds no significant difference in share price volatility between keiretsu firms and non-keiretsu firms, suggesting that both types of firms have a comparable risk-taking propensity. However, we show that keiretsu affiliates are associated with higher systematic risk and lower firm specific risk. ${ }^{3}$ The higher systematic risk of keiretsu affiliates applies to each business group and does not appear to depend on the degree of group inclination. Furthermore, the results are robust to adjustments for industry effects and firm characteristics, such as the documented larger size and higher debt ratio of keiretsu affiliates.

On the other hand, the lower idiosyncratic risk of group affiliates appears to vary across each business group. For instance, firms in the Mitsubishi and Sumitomo groups exhibit a significantly lower specific risk, while those in the DKB group exhibit a systematic risk no different from unaffiliated firms. Besides, firms with a low group inclination appear not to benefit from lower specific risk, while the result for firms with a stronger group inclination appears to be sensitive to firm characteristics, particularly firm size. Hence, bias towards lower idiosyncratic risk reported by Hamao et al. (2003) may not be the most accurate way to describe the risk taking of group affiliates. In fact, our findings suggest that higher systematic risk may be a more consistent way to describe the risk taking of keiretsu affiliates.

In any case, affiliation with a business group appears to generate more harm than benefit. As a result of fewer competitive advantages, keiretsu affiliates are more dependent on favorable

\footnotetext{
${ }^{3}$ The difference in systematic risk is consistent with Nivoix (2000) and McGuire and Dow (2002) who find that keiretsu affiliates exhibit significantly higher betas relative to unaffiliated firms.
} 
economic conditions to ensure their business performance, which explains why they have done well in the high-growth period following the end of the Second World War, and fared worse during the economic slump that has followed the burst of the asset bubble in the early 1990s. In particular, risk-sharing arrangements may have dragged down the performance of healthier firms called to support ailing affiliates. As it happens, Dewenter (2003) shows that small and highly leveraged affiliates have increased the proportion of equity sourced from their own group, whereas high-return affiliates have reduced the amount of equity supplied within their business group.

The rest of the paper is organized as follows. Section II describes the data and methodology used for testing the difference in risk taking. Section III contains the empirical results. Section IV concludes.

\section{Data and methodology}

\section{Sample}

Our base sample consists of all firms listed on the first and second sections of the Tokyo Stock Exchange (TSE) from April 1996 to March 2003. ${ }^{4}$ Financial institutions, i.e. commercial banks, securities firms and insurance companies, are excluded due to their specific economic functions. Firms with negative equity are also excluded given their potentially uncharacteristic behavior. In fact, distress situations are well known for tilting firms towards high-risk strategies. For example, Singh (1986) documents that, while the normal course of action is to reduce risk by building organizational slack, firms also tend to increase risk taking when their performance falls below acceptable levels.

We emphasize that the sample does not suffer from survivorship bias, since all firms listed on the TSE over the sample period are included. After filtering, and due to entry and exit from the panel within the period, the sample eventually consists of 1476 non-financial firms providing 10640 firm-year observations.

\footnotetext{
${ }^{4}$ This condition provides 2096 firms. About 80\% of those firms closed their accounts on 31 March, which marks Japan's fiscal year-end. Among the remaining firms, the majority closed their accounts on 31 December in the previous year.
} 
Our main data source is the NEEDS database distributed through Nikkei Financial Quest. We use the corporate information files to source firm characteristics (balance sheet, profit and loss statement and industry classification). Monthly stock prices adjusted for stock splits are retrieved from the stock market information files.

\section{Methodology}

Three variables are constructed to evaluate firm risk taking:

- Total risk (TVOL) is measured by the standard deviation of the firm's stock return using 60 monthly observations from April $t-5$ to March $t$, where $t$ denotes the current year. ${ }^{5} \mathrm{We}$ define monthly returns as the log difference in two consecutives stock prices. Unlike Beason (1998), returns are not adjusted for inflation, which has been particularly subdued over the sample period.

- Systematic risk (SYST) is defined as the return variability explained by the market model in which the market index is represented by the value-weighted return on a portfolio of all available stocks. ${ }^{6}$

- Idiosyncratic or firm-specific risk (SPEC) is defined as the residual stock return variability, i.e., total variability not explained by the market model.

More precisely, consider the return equation for firm $i$ over month $\tau$

$$
R_{i, \tau}-R F_{\tau}=\alpha_{i}+\beta_{i}\left(R M_{\tau}-R F_{\tau}\right)+\varepsilon_{i, \tau}
$$

where $R_{i}$ is firm i's monthly log return; $R F$ is a money market rate sourced from the Bank of Japan; $R M$ is the market return, proxied by the value-weighted return on a portfolio including all stocks. ${ }^{7}$ The difference $R M-R F$ represents monthly market excess returns.

For each year $t$, the return equation is estimated over the 60-month period from April $t-5$ to March $t$. Idiosyncratic risk (SPEC) is the standard deviation of the regression residual $\varepsilon$. Systematic risk (SYST) can be computed as the square root of the difference between total

\footnotetext{
${ }^{5}$ For firms closing their accounts on a different date, there is a slight mismatch between the accounting period and the window period used for estimating firm risk. However, there is no reason to believe that this mismatch results in any significant bias.

${ }^{6}$ In the case of risk-taking by financial institutions, an interest rate risk factor is usually included as a source of systematic risk. See Chen et al. (2001).

${ }^{7}$ This portfolio should provide a better market proxy than the Nikkei 225 index, which consists of the largest Japanese firms.
} 
variance (the square of TVOL) and idiosyncratic variance (the square of SPEC); i.e. $\mathrm{SYST}=\sqrt{\mathrm{TVOL}^{2}-\mathrm{SPEC}^{2}}$.

Our purpose is to evaluate whether risk taking is affected by the firm's affiliation to a keiretsu. This clearly requires a procedure to identify keiretsu affiliates. According to Gerlach (1982), affiliated firms are characterized by close trading relationships and cross-equity shareholdings with other affiliated firms, as well as regular meetings involving the presidents and top executives of the major keiretsu affiliates.

We follow Nakatani (1984) and others in focusing on the six largest horizontal (financial or bank-centered) keiretsu: DKB (Dai-ichi Kangyo), Fuyo (Fuji), Mitsubishi, Mitsui, Sanwa, and Sumitomo. Firms not affiliated to any of these groups are considered independent. This dichotomous classification, conveniently followed by many researchers, may not be as clearcut as it seems. In fact, independent firms also display strong ties with their suppliers, and often bolster these ties through cross shareholdings. ${ }^{8}$ For this reason, Gerlach (1982) argues that the distinction between affiliates and unaffiliated firms is a matter of degree. For example, although affiliated firms can pick suppliers outside their group, there is a strong expectation that a fellow affiliate will be selected. ${ }^{9}$ Several indicators can be also used to determine the boundary of the keiretsu; among others, the high proportion of capital supplied within the group and the large number of directors from other affiliates sitting on the board.

Our source for group affiliation is Industrial Groupings in Japan (1999), published by Dodwell Marketing (now Brown \& co.). This bi-annual publication also provides a measure of group inclination on a scale of 1 to 4 . Five criteria are employed to achieve this ranking: membership in the presidents' council (“shasho-kai”), percentage of cross shareholdings, percentage of cross debt holdings, importance of the group's main bank, number of directors from other affiliates. ${ }^{10}$ Although the information is available for only one year, we follow

\footnotetext{
${ }^{8}$ According to Dyer and Ouchi (1993) and Dyer (1996), close buyer-supplier relationships allow Japanese firms to overcome the well-known holdup problem and encourage suppliers to undertake the idiosyncratic investments that bring about competitive advantages.

${ }^{9}$ Gerlach (1992) estimates that keiretsu firms are about three times more likely to trade with other members in the keiretsu than with outside firms.

${ }^{10}$ The weight of each criterion is not specified in Industrial Groupings in Japan (1999).
} 
other researchers in considering that cases of firms switching affiliations are extremely uncommon (Nakatani, 1984; Gerlach, 1992).

To compare the (unadjusted) risk of keiretsu affiliates and independent firms, we use independent sample t-test for means difference and the Wilcoxon (Mann-Whitney) rank sum test for difference in medians. However, we are concerned that some risk differential could stem from industry and firm characteristics rather than being the result of keiretsu affiliation. For example, it is widely recognized that affiliated firms are larger and have more debt, which is associated with higher stock price volatility. To control for these effects, we regress each risk-taking variable on a number of control variables. Adjusted risk measures are given by the regression residuals. We then apply the same t-test and Wilcoxon (Mann-Whitney) rank sum test to evaluate the difference in adjusted risk taking by group affiliation.

Following the literature, our control variables include firm size, growth options, capital and asset structures, advertising and R\&D expenses, and industry classification. Size is measured by the natural logarithm of total sales. Although Bowman (1979) argues that there is no theoretical relation between firm size and systematic risk, several studies show that size has a negative effect on risk (e.g., Chen et al., 2001). Growth options are proxied by the market-tobook value of assets (i.e., market value of equity at year-end plus book value of liability, scaled by book value of assets). Since growth involves greater uncertainty, this variable is assumed to have a positive effect on firm risk.

We use the firm's equity ratio to measure the firm's financial leverage. The higher the equity ratio, the lower financial leverage is which implies a lower risk. Hamada (1972) and Bowman (1979) document that financial leverage has a significant positive effect on systematic risk. Cheley-Steeley and Steeley (2005) articulate the relation between total (equity) risk and asset risk, and highlight the positive effect of leverage. This effect is verified by Coles et al. (2006). We use the ratio of fixed to total assets as a proxy for operating leverage. Finance theory suggests that the degree of operating leverage has a positive effect on risk. For example, Lev (1974) and Mandelker and Rhee (1984) report a positive effect on systematic risk. Firms are also documented to offset a higher operating leverage with a lower financial leverage. In contrast, the strategic management literature considers that fixed assets are associated with competitive advantages. Hence, a higher operating leverage should result in a lower systematic risk. 
Following Coles et al. (2006), we include advertising and R\&D expenses. Both variables are measured in proportion of total sales. Since many firms do not report these figures, we use two dummies to indicate that the information is available. ${ }^{11}$ The regressions also include 27 industry dummies. The classification, which is determined by the Nikkei newsgroup, has broader segments than 2-digit SIC codes. Manufacturing industries are relatively well detailed, which is less the case of services. In the end, the adjusted risk measures relative to firm $i$ and year $t$ are given by the residuals $\eta$ of the following pooled regression:

$$
\operatorname{RISK}_{i, t}=\kappa+\gamma \text { CONTROL }_{i, t}+\eta_{i, t}
$$

where RISK $_{i, t}$ represents firm i's total, systematic or idiosyncratic risk at time $t$; while CONTROL $_{i, t}$ is a vector of control variables consisting of firm $i$ 's characteristics at time $t$ and a set of industry dummies.

\section{Results}

\section{Descriptive statistics}

Table 1 presents summary statistics for the variables used in the analysis. The risk measures are given in percentage on a monthly basis. Average monthly return volatility is about $11.9 \%$ (or $41 \%$ annually) which is comparable to the results in Hamao et al. (2003). Idiosyncratic risk is about two times higher relative to systematic risk, but nonetheless low in comparison with the US market. ${ }^{12}$

----- Please insert Table 1 about here -----

Among other firm characteristics, average market to book value of assets is about 1.17 with a significant dispersion (given a standard deviation of 0.63). The median indicates that almost half the firms have market to book ratios below one. Average equity ratio is close to 0.43 , hence does not cover the average fixed asset ratio of 0.47 . Advertising expenses exhibit a

\footnotetext{
${ }^{11}$ For more explanations regarding the interpretation of these dummies, see Himmelberg et al. (2001).

${ }^{12}$ Moreover, Hamao et al. (2003) show that idiosyncratic risk dropped dramatically following the burst of the stock market and real estate bubbles in the early 1990s. The low idiosyncratic risk of Japanese stocks is also evident in the cross-country analysis of Morck et al. (2000).
} 
significant dispersion from zero to $33 \%$ of total sales. The average estimate includes firms that did not disclose this figure. R\&D expenses exhibit an even larger dispersion from zero to $85 \%$ of total sales with an average of about $1.43 \%$. More than half the firms did not disclose that figure. Finally, about 30\% of firms are classified as affiliated with a keiretsu.

Table 2 presents pairwise correlations for the variables used in the analysis. K6 is a dummy variable indicating the affiliation to one of the 6 major keiretsu. The correlation coefficients between firm characteristics show that the equity ratio (EQTY) is positively associated with the firm's growth options (MBVA). This correlation can be explained by the higher profitability of growth firms (since a TSE listing requirement is that firms exhibit at least three years of positive earnings, which excludes high growth firms that have yet to reach that stage). Higher operating leverage (more fixed assets) is associated with lower financial leverage (higher equity ratio), which is consistent with Mandelker and Rhee (1984). Large firms (SIZE) exhibit significantly lower equity ratios, but achieve a relatively higher market to book value of assets. The first outcome is consistent with the fact that large firms are less likely to go bankrupt, while the second suggests that this lower risk is reflected in a higher firm value (consistent with structural credit risk model, e.g., Merton, 1974).

\section{----- Please insert Table 2 about here -----}

The rightmost column indicates that keiretsu affiliates are generally larger, exhibit significantly lower equity ratios, and tend to have fewer fixed assets on their balance sheet. On the other hand, their growth options seem to be comparable to those of unaffiliated firms. The bottom lines show that all risk measures are significantly correlated with most financial variables and the indicator of group affiliation (K6). Firm size is seen to reduce all measures of volatility, and in particular idiosyncratic risk. This result suggests that large firms are able to diversify some of their risk across their different business lines, hence leading to an observed lower bankruptcy risk (and credit risk premium).

Growth potential, identified by high market to book values of assets, is associated with higher risk taking, particularly regarding idiosyncratic risk, which reflects the large uncertainty surrounding future profitability. Nonetheless, the correlation coefficients appear to be relatively low despite being statistically significant. Consistent with Hamada (1972), Bowman (1979) and Christie (1982), higher financial leverage (lower equity ratio) increases systematic 
risk (as well as idiosyncratic risk). In contrast, operating leverage (ratio of fixed to total assets) appears to decrease all risk measures. This negative correlation is consistent with the view that fixed assets provide competitive advantages, which contribute to decrease the firm's risk (in particular, its systematic risk). Nonetheless reverse causality cannot be excluded if firms with lower underlying risk are more willing to increase their risk taking by increasing their operating leverage (Mandelker and Rhee, 1984).

Finally, keiretsu affiliation is not associated with higher return volatility, consistent with Beason (1998). However, we note that group affiliates are characterized by a significantly higher systematic risk and a significantly lower idiosyncratic risk.

\section{Keiretsu affiliation and risk taking}

In this section, the purpose is to compare the risk taking of affiliated and unaffiliated firms considered as two distinct groups. Although this distinction may not be so clear-cut, the results from the previous section have nevertheless highlighted some statistical differences. Hence, the question is whether the differences in performance, financing and payout behavior documented in the literature extend to risk taking.

Table 3 presents the average and median risk measures for each group of firms and the difference in risk across the two groups, unaffiliated firms serving as the control group. The upper panel involves unadjusted risk measures, while the risk measures in the lower panel are adjusted for firm and industry effects as explained in the methodology.

----- Please insert Table 3 about here -----

As suggested by the correlation analysis, the difference in total risk between affiliated and unaffiliated firms appears to be statistically insignificant. While negative, the mean difference is only $0.15 \%$ and the median even closer to zero. On the other hand, group affiliates exhibit significantly higher systematic risk as well as significantly lower idiosyncratic risk compared with unaffiliated firms. The mean difference is about $0.5 \%$ for systematic risk and $-0.6 \%$ for idiosyncratic risk. The median difference is slightly higher for systematic risk and slightly lower for idiosyncratic risk. Nonetheless, the examination of mean and median differences points to the same conclusion. 
The opposite difference in risk explains why the stock price volatility of keiretsu affiliates is not different from the stock price volatility of unaffiliated firms. This result is consistent with Beason (1998) who indicates that portfolios of keiretsu firms have a similar volatility to the portfolios of unaffiliated firms. However, the risk decomposition leads to a more refined conclusion.

Adjusted mean differences, controlling for firm characteristics, are generally half the unadjusted risk differences; yet remain statistically significant. The smaller difference indicates that firm characteristics, such as size and leverage, explain part of the risk differential of keiretsu affiliates. More precisely, the larger size of keiretsu affiliates appears to explain part of their lower systematic risk, while their lower equity and fixed asset ratios may have the opposite effect of increasing their risk. The most noticeable effect is in median difference in adjusted idiosyncratic risk, which suggests that much of the risk differential is related to firm characteristics. As a result, the difference in risk disappears when controlling for firm heterogeneity.

Consistent with the view developed in the strategic management literature, the higher systematic risk and lower idiosyncratic risk of keiretsu firms suggest that group affiliates enjoy fewer competitive advantages; hence their greater dependence on economic conditions to ensure their financial performance; and lower ability to ride out periods of economic weakness. The difficult economic environment throughout the 1990s have therefore negatively affected keiretsu affiliates much more than independent firms, contrary to the case of the high-growth period following the Second World War, during which group affiliates appeared to have outperformed unaffiliated firms. Our results underline that the interpretation of Hamao et al. (2003) is robust to various controls, including financial and operating leverage and industry classification.

\section{Risk taking by individual business groups}

The next issue is to examine whether the risk differential highlighted in the previous section is typical of all business groups or only specific to some of them. To that end, we compare the risk components for each of the 6 major business groups. In other words, our purpose is to disaggregate the results found when all keiretsu firms were considered as a single group. 
Table 4 presents the difference in risk between affiliates of each business group and unaffiliated firms representing the control group. The risk levels can easily be reconstructed by adding the risk level of unaffiliated firms using the data in Table 3. Consider first unadjusted risk. The fact that some business groups (DKB) have a higher total risk while others have a lower total risk (Mitsubishi and Sumitomo) explains why total risk for affiliated firms taken altogether is not significant different from unaffiliated firms. In contrast, all groups present a higher systematic risk and most present a lower firm specific risk. Both mean and median differences lead to the same interpretation.

----- Please insert Table 4 about here -----

Two groups appear to exemplify the effect of keiretsu affiliation on risk taking: The Mitsubishi and Sumitomo groups have significantly lower idiosyncratic risk, which is reflected overall in their lower stock price volatility, in spite of a significantly higher systematic risk. In contrast, the higher stock price volatility of the DKB group, which is uncharacteristic of keiretsu affiliates, appears to be the result of higher systematic risk, but insignificantly different idiosyncratic risk. The combination of higher systematic risk and generally lower idiosyncratic risk suggests that none of the main business groups has been successful in developing market power through product differentiation and/or genuine cost advantage. The worst performer may be Mitsubishi. Interestingly, the troubles experienced by some prominent Mitsubishi affiliates, such as Mitsubishi Motors (MMC), appear to be correctly reflected in the group's risk parameters. ${ }^{13}$ Yoshikawa and Phan (2001) compare the financial and stock price performance of another affiliate, Mitsubishi Electric, with Sony, an independent firm, and show that the difference is overwhelmingly in favor of Sony. ${ }^{14}$

Consider next, adjusted risk measures. As noted in the case where all affiliates were combined together, controlling for firm characteristics and industry effects reduces the difference in risk taking. Most individual groups appear to display a higher systematic risk. With the notable exception of Sumitomo, differences in systematic risk remain significant for each group. On

\footnotetext{
${ }^{13}$ The following titles leave no doubt concerning the extent of the automaker's woes, "Mitsubishi flounders in a sea of troubles," BRW, 11/24/1997; "Stalled,” Business Week, 9/29/2003; "Mitsubishi drives into gridlock of problems,” Media Asia, 6/18/2004.

${ }^{14}$ Over the 7-year period from 1993 to 1999, Sony's stock price increased by over 600\% while Mitsubishi Electric's stock price moved up by only $36 \%$.
} 
the other hand, median differences in adjusted idiosyncratic risk turn out to be less significant. This less consistent difference between affiliated and unaffiliated firms suggests that higher systematic risk may be more characteristic of keiretsu affiliation than the lower idiosyncratic risk emphasized in Hamao et al. (2003). ${ }^{15}$

\section{Group inclination and risk taking}

Our last concern is to examine the influence of group inclination on risk taking. As Gerlach (1992) observes, affiliated firms enjoy a certain degree of freedom in choosing their trading partners and sources of funding. Some affiliates take part in the regular presidents' meeting while others are much less involved. As a result, weakly affiliated firms may not be thoroughly different from unaffiliated firms, which also benefit from close relationships with their own network of suppliers and fund providers.

Table 5 presents the difference in risk by degree of group inclination considering unaffiliated firms as the control group. Using both adjusted and unadjusted measures, systematic risk appears to be significantly positive regardless of the firm's inclination to its group. On the other hand, the degree of group inclination appears to affect the level of idiosyncratic risk. In particular, firms with a high (i.e., second highest) group inclination appear to be characterized by higher instead of lower idiosyncratic risk. The difference is significant using unadjusted median risk, while the positive mean difference is statistically insignificant. Accordingly, firms with a high group inclination exhibit higher stock price volatility.

----- Please insert Table 5 about here -----

Core group firms (i.e., highest inclination) exhibit lower stock price volatility, which indicates that a significant amount of risk diversification is achieved at the heart of the keiretsu network, consistent with principles of modern portfolio theory. Using adjusted risk measures, the signs appear to flip for core and highly inclined firms (i.e., for firms with inclinations 3 and 4). The

\footnotetext{
${ }^{15}$ This emphasis may be justified by the recent interpretation of idiosyncratic risk in relation to the diffusion of firm-specific information through stock prices. For instance, Morck et al. (2000) find that lower idiosyncratic risk relative to systematic risk (i.e., lower return synchronicity) is associated with lower profitability and economic growth in emerging markets. The basic idea is that informed prices contribute to guide the flow of capital across industry sectors. Durnev et al (2004) also show that idiosyncratic risk is positively correlated with optimal capital budgeting, estimated by the proximity of marginal Tobin's Q to a best possible level considered to be 1 , which suggests that idiosyncratic risk may also improve the allocation of resources within the firm.
} 
reason is essentially related to the smaller size of highly inclined firms. Since smaller size is associated with higher risk, correcting for size results in lower adjusted (idiosyncratic) risk. The size effect works in the opposite direction for core firms, which are characterized by larger size; hence their higher adjusted (idiosyncratic) risk.

Overall, the strong association between firm size and group inclination makes idiosyncratic risk difficult to interpret. Hence, the most reliable conclusion is perhaps the consistently higher systematic risk displayed by keiretsu firms regardless of their group inclination. In addition, although their idiosyncratic risk appears to be unaffected by their keiretsu status, weakly inclined firms are nevertheless associated with a higher systematic risk. This result suggests that, at the fringe of the keiretsu network, firms benefit little from risk diversification and other economic advantages, but are instead strongly reliant on the performance of the major keiretsu affiliates.

\section{Compensation for risk taking}

Given that keiretsu affiliates exhibit a higher level of systematic risk, one can expect them to provide a higher return. To investigate this issue, ${ }^{16}$ we group affiliated and independent firms in two equal-weighted portfolios and compare their monthly average returns. Table 6 shows that the difference over the whole sample period is positive, but statistically and economically insignificant, which seems to suggest that Japanese investors are not rewarded for taking systematic risk.

----- Please insert Table 6 about here -----

In fact, unconditional tests of the (systematic) risk-return relationship often produce insignificant slope coefficients, leading some researchers to question the usefulness of the market index as a priced risk factor. Pointing out that realized market excess returns can be negative, while expected market excess returns must be positive, Pettengill et al. (1995) propose to distinguish between up and down markets; that is to say according to the realized return on the market index in excess of the risk-free rate. When this distinction is made, the risk-return relationship becomes significantly positive in up markets, and significantly negative in down markets. Tang and Shum (2006) report a similar result for the Hong Kong stock market.

\footnotetext{
${ }^{16}$ We thank the referee for suggesting this investigation.
} 
In the case of Japan, the financial crisis following the burst of the asset bubble in the early 1990s is likely to have undermined the risk-return relationship due to the unusual long time it took most stocks to recover from the crisis. To tackle this problem, we separate monthly observations according to the sign (and magnitude) of market excess returns. In up markets, keiretsu firms appear to produce returns $0.59 \%$ higher than independent firms. In down markets, their returns tend to be $0.42 \%$ lower. In both cases, the difference is significant at less than 1\%. These results support our established view that keiretsu affiliates present a higher systematic risk. Furthermore, this impression is verified by considering the magnitude of market movements. As it happens, the larger the market excess return, the larger the returns of keiretsu affiliates. However, the opposite occurs in down markets, with the stock price of keiretsu affiliates falling significantly more relative to other firms, which highlights their greater market (systematic) risk.

Besides, the results suggest that under normal conditions, when equity investments provide a positive excess return over the risk-free rate, higher systematic risk will tend to be associated with higher returns. Here, because the Japanese stock market has been trading directionless over most of the sample period, it was inevitable to find little difference in realized returns despite significant differences in systematic risk. Since the financial crisis took place from the early 1990s until about 2002, we partition the sample in two sub-periods. Over the first period ending in 2002, the average return of keiretsu firms is comparable to the return of other firms, as the market records a similar number of up and down movements (63 months up for 75 months down). Over the second period from January 2003 to June 2007, during which the market has trended up with 34 months up for 19 months down, keiretsu affiliates exhibit an average return $0.43 \%$ higher than other firms (significant at $1 \%$ ). In addition, untabulated results indicate that all the main business groups achieved higher returns. Hence, although the realized premium for investing in affiliated firms has been (ex post) negligible, investors can normally expect a higher return (ex ante) for bearing their higher systematic risk.

\section{Conclusion}

In this paper, we have analyzed the influence of keiretsu affiliation on the risk taking of Japanese firms. The issue is important since risk taking is as much associated with financial distress as it is associated with financial performance. In fact, the type of risk taken by firms 
has significant implications. Our results demonstrate that keiretsu affiliates are characterized by lower idiosyncratic risk and higher systematic risk.

The lower idiosyncratic risk is consistent with the lower earnings volatility documented by Nakatani (1984) and suggests the existence of risk sharing among keiretsu affiliates. Consistent this view, Hamao et al. (2003) argue that transfers from healthier firms to distressed ones have resulted in less differentiated stock price performance. However, the difference might have been caused by factors unrelated to keiretsu affiliation. After adjusting for various firm characteristics, we find that keiretsu affiliates present idiosyncratic risk levels insignificantly different from those of other firms. In addition, idiosyncratic risk appears to vary across each business group and with the degree of the firm's inclination toward its group.

A more consistent result is the higher systematic risk displayed by affiliated firms. This result cannot be explained by risk sharing, but supports the view that keiretsu affiliates are less competitive, perhaps due to overly cautious investment policies (Weinstein and Yafeh, 1998) or due to the burden of supporting weaker affiliates (Hoshi et al., 1990; Dewenter, 2003). As a consequence, keiretsu affiliates have become more vulnerable and less able to weather economy-wide fluctuations. As with idiosyncratic risk, higher systematic risk is partly explained by firm characteristics, and in particular, the higher debt ratio of keiretsu members. Nonetheless, adjusted systematic risk remains significantly higher compared with unaffiliated firms. Besides, all major groups appear to exhibit a higher systematic risk; and this higher systematic risk is significant regardless of the firm's inclination to its business group.

Although there appears to be some risk sharing among keiretsu affiliates, leading to somewhat lower idiosyncratic risk, the critical result is the significantly higher systematic risk associated with keiretsu affiliation. As suggested in the strategic management literature (e.g., Porter, 1980), this higher systematic risk is consistent with the greater difficulties faced by keiretsu affiliates when economic conditions began to deteriorate in Japan. Hence, the protection offered by group affiliation appears to have serious drawbacks. By sheltering weaker firms from competitive forces, business groups appear to have hindered the powers of creative destruction and, in the process, may have weakened healthier affiliated firms (Hamao et al., 2003). Accordingly, the results support the unraveling of cross shareholdings and question the benefits of keiretsu affiliation. 


\section{References}

Beason, D., 1998, Keiretsu affiliation and share price volatility in Japan, Pacific-Basin Finance Journal 6, 27-43

Bowman, R., 1979, The Theoretical Relationship Between Systematic Risk and Financial (Accounting) Variables, Journal of Finance, 34, 617-630

Chelley-Steeley, P. and J. Steeley, 2005, The leverage effect in the UK stock market, Applied Financial Economics 15, 409-423.

Chen, C., Steiner, T., and A. White, 2001, Risk taking behavior and managerial ownership in the United States life insurance industry, Applied Financial Economics 11, 165-171.

Christie, A., 1982, The Stochastic Behavior of Common Stock Variances: Value, Leverage and Interest Rate Effects, Journal of Financial Economics, 10, 407-432

Coles, J., Daniel, N., and L. Naveen, 2006, Managerial incentives and risk-taking, Journal of Financial Economics 79, 431-468

Dewenter, K., 2003, The risk-sharing role of Japanese keiretsu business groups: evidence from restructuring in the 1990s, Japan and the World Economy 15, 261-274.

Durnev, A., Morck, R., and B. Yeung, 2004, Value-enhancing capital budgeting and firm-specific stock return variation, Journal of Finance 59, 65-105

Dyer, J., 1996, Specialized supplier networks as a source of competitive advantage: Evidence from the auto industry, Strategic Management Journal, 17, pp. 271-291.

Dyer, J. and W. Ouchi, 1993, Japanese style business partnerships: Giving companies a competitive edge, Sloan Management Review 35, pp. 51-63.

Gerlach, M., 1992, Twilight of the Keiretsu? A Critical Assessment, Journal of Japanese Studies 18, $79-118$

Hamada, R., 1972, The effect of the firms capital structure on the systematic risk of common stocks, Journal of Finance 27, 435-452.

Hamao, Y., Mei, J., and Y. Xu, 2003, Idiosyncratic risk and the creative destruction in Japan, NBER Working Paper 9642

Himmelberg, C., Hubbard, G., and D. Palia, 1999, Understanding the determinants of managerial ownership and the link between ownership and performance, Journal of Financial Economics 53, 353-384

Hoshi, T., Kashyap, A., and D. Scharfstein, 1990, The role of banks in reducing the costs of financial distress in Japan, Journal of Financial Economics 27, 67-88.

Houston, J., and C. James, 1996, Bank information monopolies and the mix of private and public debt claims, Journal of Finance 51, 1863-1889.

Lev, B., 1974, On the association between operating leverage and risk, Journal of Financial and Quantitative Analysis 9, 627-641

Lubatkin, M., and H. O'Neill, 1987, Merger strategies and capital market risk, Academy of Management Journal, 30, 665-84

Mandelker, G. and G. Rhee, 1984, The impact of the degrees of operating and financial leverage on systematic risk of common stock, Journal of Financial and Quantitative Analysis 19, 45-57.

Merton, R., 1974, On the Pricing of Corporate Debt: The risk structure of interest rates, Journal of Finance 28, 449-470. 
Morck, R., Yeung, B., and W. Yu, 2000, The information content of stock markets: why do emerging markets have synchronous stock price movements? Journal of Financial Economics 58, 215260

Nakatani, I., 1984, The economic role of financial corporate grouping. In: Aoki, M. (Ed.), The Economic Analysis of the Japanese Firm, North-Holland, 227-258.

Nivoix, S., 2000, The ownership structure and systematic risk of Japanese firms, Working paper, CEREGE - University of Poitiers, France.

McGuire, J., and S. Dow, 2002, The persistence and implications of Japanese keiretsu organization, Journal of International Business Studies 34, 374-388.

Pettengill, G., Sundaram, S. and I. Mathur, 1995, The conditional relation between beta and returns, Journal of Financial and Quantitative Analysis, 30, 101-116.

Porter, M., 1980, Competitive strategy: Techniques for analyzing industries and competitors, New York: Free Press.

Rumelt, R., 1974, Strategy, structure, and economic performance, Cambridge, MA: Harvard University Press.

Sheard, P., 1989, The Japanese general trading company as an aspect of inter-firm risk-sharing, Journal of the Japanese and International Economies 3, 308-322.

Singh, J., 1986, Performance, slack, and risk taking in organizational decision making, Academy of Management Journal, 29, 562-585

Suzuki S., and R. Wright, 1985, Financial structure and bankruptcy risk in Japanese companies, Journal of International Business Studies 16, 97-110.

Tang, G., and W. Shum, 2006, Risk-return relationships in the Hong Kong stock market: revisit, Applied Financial Economics 16, 1047 - 1058

Walker, M. and C. Hsu, 2007, Strategic objectives, industry structure and the long-term stock price performance of acquiring and rival firms, Applied Financial Economics 17, 1233 - 1244.

Weinstein, D. and Y. Yafeh, 1998, On the costs of a bank centered financial system: evidence from the changing main-bank relations in Japan, Journal of Finance 53, 635-672.

Yoshikawa, T. and P. Phan, 2001, Alternative corporate governance systems in Japanese firms: Implications for a shift to stockholder-centered corporate governance, Asia Pacific Journal of Management 18, 183-205. 
Table 1: Descriptive statistics

\begin{tabular}{lrrrrr}
\hline & Mean & Median & Std. Dev. & Min & Max \\
\hline & & & & & \\
TVOL $(\times 100)$ & 11.8879 & 11.3021 & 4.2818 & 1.7519 & 43.8526 \\
SYST $(\times 100)$ & 5.4815 & 5.4014 & 2.6257 & 1.2703 & 19.3891 \\
SPEC $(\times 100)$ & 10.3531 & 9.6494 & 3.9408 & 1.7154 & 42.1805 \\
& & & & & \\
SIZE & 11.0713 & 10.9463 & 1.3663 & 6.4118 & 16.5558 \\
MBVA & 1.1700 & 1.0348 & 0.6353 & 0.2361 & 16.0862 \\
EQTY & 0.4298 & 0.4223 & 0.2133 & 0.0290 & 0.9981 \\
FIXED & 0.4654 & 0.4628 & 0.1843 & 0.0046 & 0.9938 \\
& & & & & \\
ADVERT & 0.7836 & 0.1600 & 1.8433 & 0 & 33.14 \\
RD & 1.4312 & 0 & 2.9170 & 0 & 84.92 \\
K6 & 0.3006 & 0 & 0.4585 & 0 & 1 \\
\hline
\end{tabular}

Notes: TVOL is the standard deviation of monthly stock returns. SYST is the stock return variation explained by market model. SPEC is the standard deviation of the regression residual. SIZE is the natural log of the firm's total sales in million yen. MBVA is the market to book value of assets. EQTY is book value of equity to total assets. FIXED is the ratio of fixed assets to total assets. ADVERT is the ratio of advertising expenses to sales. $\mathrm{RD}$ is the ratio of $\mathrm{R} \& \mathrm{D}$ expenses to sales. K6 indicates that the firm is affiliated with one of the six major business groups. 
Table 2: Correlation structure of main variables

\begin{tabular}{lccccc}
\hline & SIZE & MBVA & FIXED & EQTY & K6 \\
\hline & & & & & \\
SIZE & & $0.0797^{*}$ & -0.0107 & $-0.2204^{*}$ & $0.1975^{*}$ \\
MBVA & & & 0.0014 & $0.1180^{*}$ & -0.0173 \\
FIXED & & & & $0.0355^{*}$ & $-0.0737^{*}$ \\
EQTY & & & & & $-0.1780^{*}$ \\
& & & & & \\
TVOL & $-0.2786^{*}$ & $0.0354^{*}$ & $-0.1215^{*}$ & $-0.1606^{*}$ & -0.0166 \\
SYST & $-0.1166^{*}$ & 0.0154 & $-0.1622^{*}$ & $-0.1345^{*}$ & $0.0960^{*}$ \\
SPEC & $-0.2964^{*}$ & $0.0376^{*}$ & $-0.0951^{*}$ & $-0.1442^{*}$ & $-0.0487^{*}$ \\
\hline
\end{tabular}

Notes: TVOL is the standard deviation of monthly stock returns. SYST is the stock return variation explained by market model. SPEC is the standard deviation of the regression residual. SIZE is the natural log of the firm's total sales. MBVA is the market to book value of assets. EQTY is book value of equity to total assets. FIXED is the ratio of fixed assets to total assets. K6 indicates that the firm is affiliated with one of the six major business groups. * indicates statistical significance at the $1 \%$ level. 
Table 3: Risk-taking by keiretsu affiliation

\begin{tabular}{|c|c|c|c|}
\hline & $\begin{array}{l}\text { Total risk } \\
\text { (TVOL) }\end{array}$ & $\begin{array}{l}\text { Market Risk } \\
\text { (SYST) }\end{array}$ & $\begin{array}{l}\text { Specific Risk } \\
\text { (SPEC) }\end{array}$ \\
\hline \multicolumn{4}{|l|}{ Mean (unadjusted) } \\
\hline - Affiliated & 11.780 & 5.866 & 10.061 \\
\hline - Independent & 11.934 & 5.316 & 10.479 \\
\hline $\begin{array}{l}\text { Mean difference } \\
\text { t-value }\end{array}$ & $\begin{array}{l}-0.155 * \\
(-1.84)\end{array}$ & $\begin{array}{l}0.550 * * * \\
(10.84)\end{array}$ & $\begin{array}{l}-0.418 * * * \\
(-5.38)\end{array}$ \\
\hline \multicolumn{4}{|l|}{ Median (unadjusted) } \\
\hline - Affiliated & 11.279 & 5.815 & 9.478 \\
\hline - Independent & 11.310 & 5.176 & 9.758 \\
\hline $\begin{array}{l}\text { Median difference } \\
\text { z-value }\end{array}$ & $\begin{array}{l}-0.031 \\
(-0.03)\end{array}$ & $\begin{array}{l}0.639 * * * \\
(11.43)\end{array}$ & $\begin{array}{l}-0.280 * * * \\
(-4.02)\end{array}$ \\
\hline \multicolumn{4}{|l|}{ Adjusted mean } \\
\hline - Affiliated & -0.007 & 0.226 & -0.100 \\
\hline - Independent & 0.003 & -0.097 & 0.043 \\
\hline $\begin{array}{l}\text { Adjusted mean difference } \\
\text { t-value }\end{array}$ & $\begin{array}{l}-0.010 \\
(-0.13)\end{array}$ & $\begin{array}{l}0.323 * * * \\
(7.32)\end{array}$ & $\begin{array}{l}-0.143 * * \\
(-2.20)\end{array}$ \\
\hline \multicolumn{4}{|l|}{ Adjusted median } \\
\hline - Affiliated & -0.287 & 0.181 & -0.423 \\
\hline - Independent & -0.453 & -0.174 & -0.419 \\
\hline $\begin{array}{l}\text { Adjusted median difference } \\
\text { z-value }\end{array}$ & $\begin{array}{l}0.166 * \\
(1.88)\end{array}$ & $\begin{array}{l}0.355^{* * *} \\
(8.16)\end{array}$ & $\begin{array}{l}-0.004 \\
(-0.66)\end{array}$ \\
\hline
\end{tabular}

Notes: All risk measures are expressed in percentage. TVOL is the standard deviation of monthly stock returns. SYST is the stock return variation explained by market model. SPEC is the standard deviation of the regression residual using the market model. Adjusted risk is the residual of the regression of unadjusted risk on various firm characteristics. Affiliation is with respect to one of the six major business groups. Unaffiliated firms are deemed independent. $* * *, * *, *$ denote statistical significance at the $1 \%, 5 \%$ and $10 \%$ levels. 
Table 4: Risk taking by individual keiretsu

\begin{tabular}{|c|c|c|c|c|c|c|}
\hline & \multicolumn{2}{|c|}{$\begin{array}{r}\text { Total Risk } \\
\text { (TVOL) }\end{array}$} & \multicolumn{2}{|c|}{$\begin{array}{c}\text { Market Risk } \\
\text { (SYST) }\end{array}$} & \multicolumn{2}{|c|}{$\begin{array}{r}\text { Specific Risk } \\
\text { (SPEC) }\end{array}$} \\
\hline \multicolumn{7}{|c|}{ Mean difference (unadjusted) } \\
\hline DKB & 0.462 & $(2.42) * *$ & 0.914 & $(8.96) * * *$ & 0.060 & $(0.33)$ \\
\hline Fuji & -0.184 & $(-1.11)$ & 0.477 & $(4.69) * * *$ & -0.389 & $(-2.58) * *$ \\
\hline Mitsubishi & -0.597 & $(-4.57) * * *$ & 0.469 & $(5.08) * * *$ & -0.870 & $(-7.39) * * *$ \\
\hline Mitsui & 0.128 & $(0.70)$ & 0.825 & $(7.31) * * *$ & -0.249 & $(-1.44)$ \\
\hline Sanwa & -0.170 & $(-1.07)$ & 0.468 & $(5.18) * * *$ & -0.365 & $(-2.46) * *$ \\
\hline Sumitomo & -0.403 & $(-2.20) * *$ & 0.282 & $(2.55) * *$ & -0.592 & $(-3.49) * * *$ \\
\hline \multicolumn{7}{|c|}{ Median difference (unadjusted) } \\
\hline DKB & 0.282 & $(2.73) * * *$ & 0.943 & $(8.48) * * *$ & -0.111 & $(0.11)$ \\
\hline Fuji & 0.146 & $(0.59)$ & 0.587 & $(4.86) * * *$ & -0.124 & $(-1.00)$ \\
\hline Mitsubishi & -0.149 & $(-1.58)$ & 0.717 & $(5.26) * * *$ & -0.451 & $(-3.68) * * *$ \\
\hline Mitsui & 0.132 & $(1.70) *$ & 0.891 & $(6.88) * * *$ & -0.095 & $(-0.39)$ \\
\hline Sanwa & -0.275 & $(-0.52)$ & 0.595 & $(4.87) * * *$ & -0.169 & $(-1.93) *$ \\
\hline Sumitomo & -0.610 & $(-2.29) * *$ & 0.312 & $(2.56) * *$ & -0.728 & $(-4.06) * * *$ \\
\hline \multicolumn{7}{|c|}{ Adjusted mean difference } \\
\hline DKB & 0.400 & $(2.45) * *$ & 0.508 & $(5.33) * * *$ & 0.203 & $(1.31)$ \\
\hline Fuji & -0.258 & $(-1.85) *$ & 0.176 & $(2.11) * *$ & -0.325 & $(-2.57) * *$ \\
\hline Mitsubishi & -0.148 & $(-1.33)$ & 0.376 & $(4.64) * * *$ & -0.323 & $(-3.20) * * *$ \\
\hline Mitsui & 0.215 & $(1.25)$ & 0.765 & $(6.88) * * *$ & -0.114 & $(-0.72)$ \\
\hline Sanwa & 0.048 & $(0.36)$ & 0.239 & $(3.16) * * *$ & -0.013 & $(-0.10)$ \\
\hline Sumitomo & -0.222 & $(-1.48)$ & 0.047 & $(0.49)$ & -0.276 & $(-1.99) * *$ \\
\hline \multicolumn{7}{|c|}{ Adjusted median difference } \\
\hline DKB & 0.241 & $(2.72) * * *$ & 0.537 & $(5.55) * * *$ & 0.080 & $(1.16)$ \\
\hline Fuji & 0.288 & $(0.29)$ & 0.297 & $(2.63) * * *$ & 0.024 & $(-0.58)$ \\
\hline Mitsubishi & 0.331 & (1.11) & 0.478 & $(4.94) * * *$ & 0.081 & $(-0.40)$ \\
\hline Mitsui & 0.207 & $(1.84) *$ & 0.943 & $(7.17) * * *$ & -0.110 & $(-0.31)$ \\
\hline Sanwa & 0.132 & $(0.53)$ & 0.224 & $(2.94) * * *$ & 0.040 & $(-0.03)$ \\
\hline Sumitomo & -0.112 & $(-0.88)$ & 0.006 & $(0.70)$ & -0.166 & $(-1.67) *$ \\
\hline
\end{tabular}

Notes: All risk measures are expressed in percentage. TVOL is the standard deviation of monthly stock returns. SYST is the stock return variation explained by the market model. SPEC is the standard deviation of the regression residual using the market model. Adjusted risk is the residual of the regression of unadjusted risk on various firm characteristics. Mean and median differences are relative to unaffiliated firms. ${ }^{* * *}, * *, *$ denote statistical significance at the $1 \%, 5 \%$ and $10 \%$ levels. 
Table 5: Risk taking by degree of group inclination

\begin{tabular}{ccc}
\hline $\begin{array}{c}\text { Total Risk } \\
\text { (TVOL) }\end{array}$ & $\begin{array}{c}\text { Market Risk } \\
\text { (SYST) }\end{array}$ & $\begin{array}{c}\text { Specific Risk } \\
\text { (SPEC) }\end{array}$ \\
\hline
\end{tabular}

Mean difference

inclination

\begin{tabular}{|c|c|c|c|c|c|c|}
\hline Low $=1$ & 0.085 & $(0.35)$ & 0.615 & $(4.04) * * *$ & -0.161 & $(-0.78)$ \\
\hline 2 & -0.281 & $(-1.87) *$ & 0.289 & $(3.32) * * *$ & -0.410 & $(-2.94) * * *$ \\
\hline 3 & 0.518 & $(4.51) * * *$ & 0.845 & $(11.90) * * *$ & 0.176 & (1.64) \\
\hline High $=4$ & -0.922 & $(-6.59) * * *$ & 0.332 & $(4.02) * * *$ & -1.191 & $(-9.07) * * *$ \\
\hline
\end{tabular}

Median difference

inclination

\begin{tabular}{|c|c|c|c|c|c|c|}
\hline Low $=1$ & 0.206 & $(0.71)$ & 0.658 & $(3.96) * * *$ & -0.248 & $(-0.35)$ \\
\hline 2 & -0.203 & $(-1.19)$ & 0.391 & $(3.82) * * *$ & -0.308 & $(-2.53) * *$ \\
\hline 3 & 0.578 & $(6.37) * * *$ & 0.894 & $(11.48) * * *$ & 0.369 & $(3.70) * * x$ \\
\hline High $=4$ & -0.805 & $(-5.53) * * *$ & 0.442 & $(4.40) * * *$ & -1.110 & $(-8.67) * * *$ \\
\hline
\end{tabular}

Adjusted mean difference

inclination

\begin{tabular}{|c|c|c|c|c|c|c|}
\hline Low $=1$ & 0.202 & (1.13) & 0.594 & $(4.99) * * *$ & 0.008 & $(-0.16)$ \\
\hline 2 & -0.050 & $(-0.37)$ & 0.232 & $(2.94) * * *$ & -0.089 & $(-1.03)$ \\
\hline 3 & -0.125 & $(-1.16)$ & 0.368 & $(5.73) * * *$ & -0.257 & $(-2.96) * * *$ \\
\hline ligh $=4$ & 0.289 & $(2.68) * * *$ & 0.261 & $(3.84) * * *$ & 0.226 & $(1.88) *$ \\
\hline
\end{tabular}

Adjusted median difference

inclination

\begin{tabular}{|c|c|c|c|c|c|c|}
\hline Low $=1$ & 0.308 & $(1.72) *$ & 0.433 & $(4.59) * * *$ & 0.039 & $(0.47)$ \\
\hline 2 & 0.114 & (0.63) & 0.433 & $(3.88) * * *$ & -0.004 & $(-0.29)$ \\
\hline 3 & 0.057 & $(-0.29)$ & 0.421 & $(6.16) * * *$ & -0.055 & $(-2.70) * * *$ \\
\hline High $=4$ & 0.481 & $(4.33) * * *$ & 0.304 & $(4.11) * * *$ & 0.266 & $(3.61) * * *$ \\
\hline
\end{tabular}

Notes: All risk measures are expressed in percentage. TVOL is the standard deviation of monthly stock returns. SYST is the stock return variation explained by the market model. SPEC is the standard deviation of the regression residual using the market model. Adjusted risk is the residual of the regression of unadjusted risk on various firm characteristics. Mean and median differences are relative to unaffiliated firms. Keiretsu inclination is from Industrial Groupings in Japan (1999). ***, **, * denote statistical significance at the $1 \%, 5 \%$ and $10 \%$ levels. 
Table 6: Average monthly returns by keiretsu affiliation

\begin{tabular}{|c|c|c|c|c|c|}
\hline & $\mathrm{N}$ & Affiliated & Independent & Difference & (t-value) \\
\hline Total sample period & 192 & 0.29 & 0.20 & 0.10 & $(0.90)$ \\
\hline Up market & 98 & 4.52 & 3.93 & 0.59 & $(4.02) * * *$ \\
\hline Down market & 94 & -4.11 & -3.69 & -0.42 & $(-3.10) * * *$ \\
\hline \multicolumn{6}{|c|}{ Magnitude of positive market excess return } \\
\hline$>0.05$ & 25 & 9.45 & 7.96 & 1.49 & $(3.62) * * *$ \\
\hline$>0.04$ & 41 & 7.93 & 6.86 & 1.07 & $(3.81) * * *$ \\
\hline$>0.03$ & 56 & 6.75 & 5.88 & 0.87 & $(3.92) * * *$ \\
\hline$>0.02$ & 64 & 6.27 & 5.50 & 0.77 & $(3.87) * * *$ \\
\hline$>0.01$ & 79 & 5.45 & 4.74 & 0.71 & $(4.18) * * *$ \\
\hline \multicolumn{6}{|c|}{ Magnitude of negative market excess return } \\
\hline$<-0.01$ & 78 & -5.08 & -4.49 & -0.59 & $(-4.37) * * *$ \\
\hline$<-0.02$ & 63 & -5.75 & -5.02 & -0.73 & $(-4.70) * * *$ \\
\hline$<-0.03$ & 52 & -6.24 & -5.38 & -0.87 & $(-5.07) * * *$ \\
\hline$<-0.04$ & 35 & -7.16 & -6.22 & -0.94 & $(-4.57) * * *$ \\
\hline$<-0.05$ & 27 & -7.50 & -6.47 & -1.04 & $(-4.13) * * *$ \\
\hline \multicolumn{6}{|c|}{ Analysis by sub-periods } \\
\hline Jul 1991 - Dec 2002 & 138 & -0.51 & -0.47 & -0.04 & $(-0.27)$ \\
\hline Jan 2003 - Jun 2007 & 54 & 2.34 & 1.91 & 0.43 & $(2.87) * * *$ \\
\hline
\end{tabular}

Notes: Average returns are expressed in percentage per month. Affiliation is with respect to one of the six major business groups. Unaffiliated firms are considered independent. Up and down markets are identified by the sign of the market excess return over the risk-free rate. $* * *, * *, *$ denote statistical significance at the $1 \%, 5 \%$ and $10 \%$ levels. 